\title{
Ambiente virtual de aprendizagem: contribuiçóes da terapia ocupacional a pais e familiares na assistência de crianças com anomalias craniofaciais ${ }^{1}$
}

\author{
Lyana Carvalho e Sousa ${ }^{a}$, Márcia Cristina Almendros Fernandes Moraes ${ }^{\mathrm{b}}$, \\ Caroline Duchatsch Ribeiro de Souza ${ }^{\mathrm{b}}$, Hélcio da Silva ${ }^{a}$, Élvio Gilberto da Silva ${ }^{a}$, \\ Leonardo Coelho Souza dos Reis ${ }^{a}$, Patrick Pedreira Silva ${ }^{a}$, Luciana Paula Maximino \\ aniversidade do Sagrado Coração - USC, Bauru, SP, Brasil. \\ ${ }^{\text {b} H o s p i t a l ~ d e ~ R e a b i l i t a c ̧ a ̃ o ~ d e ~ A n o m a l i a s ~ C r a n i o f a c i a i s ~-~ H R A C, ~ B a u r u, ~ S P, ~ B r a s i l . ~}$ \\ 'Departamento de Fonoaudiologia, Universidade de São Paulo - USP, Bauru, SP, Brasil.
}

\begin{abstract}
Resumo: Introdução: As fissuras labiopalatinas estão entre as malformações de maior incidência entre as anomalias congênitas. O Hospital de Reabilitação de Anomalias Craniofaciais da Universidade de São Paulo, em Bauru, assiste a essa clientela de toda a América Latina por meio de uma equipe interdisciplinar de referência. Como o tratamento adequado demanda vários anos de intervenção e cuidados, as famílias das crianças com esse tipo de anomalia acabam se deparando com barreiras de caráter financeiro e geográfico que dificultam o acesso à terapia. Diante disso, o uso de ferramentas digitais na comunicação entre profissionais da saúde e os responsáveis pelos pacientes é um potencial recurso na transmissão de conhecimento. Objetivo: Criar e avaliar um ambiente virtual de aprendizagem sobre o desenvolvimento de crianças com anomalias craniofaciais, usando técnicas de terapia ocupacional. Método: Foi criado um ambiente virtual (website) usando e adaptando o Health-Related Web Site Evaluation Form Emory. O website foi então avaliado por cinco terapeutas ocupacionais e cinco fonoaudiólogos e o resultado foi submetido à análise descritiva e tratamento quanti-qualitativo, também usando as características e formas de análise do Emory. Resultados: A qualidade do site foi considerada "Adequada" por 81,1\% dos avaliadores, enquanto o conteúdo por faixa etária foi considerado "Excelente" por 94,3\%. Conclusão: O uso do ambiente virtual no tratamento de crianças com fissuras labiopalatinas foi relevante, mostrando-se adequado e com conteúdo excelente ao fim ao qual se destina. Isso indica, portanto, que o desenvolvimento tecnológico pode beneficiar processos terapêuticos e facilitar o acesso a este tratamento específico.
\end{abstract}

Palavras-chave: Telemedicina, Terapia Ocupacional, Desenvolvimento Infantil, Anormalidades Craniofaciais.

\section{Virtual learning environment: occupational therapy contributions to parents and families caring for children with craniofacial abnormalities}

\begin{abstract}
Introduction: Cleft lip and palate are among the most prevalent congenital malformations in mankind. The Craniofacial Anomalies Rehabilitation Hospital of the University of São Paulo in Bauru provides assistance for these patients from all over Latin America through a reference interdisciplinary team. The treatment requires several years of intervention and care; parents and caregivers end up facing financial and geographical hurdles to access this care. Thus, the use of virtual tools to improve the communication between health care providers and the adults responsible for children with cleft lip and palate is a potential resource to pass on knowledge. Objective: To create and evaluate a virtual learning environment for the development of children with craniofacial anomalies
\end{abstract}

Autor para correspondência: Lyana Carvalho e Sousa, Universidade do Sagrado Coração, Rua Irmã Arminda, 10-50, Jardim Brasil, CEP 17011-160, Bauru, SP, Brasil, e-mail: lyana.sousa@gmail.com

Recebido em Jul. 01, 2016; $1^{\text {a }}$ revisão em Nov. 21, 2016; 2ª Revisão em Fev. 1, 2017; Aceito em Fev. $21,2017$. 
using occupational therapy techniques. Method: A virtual environment (website) was created using an adapted version of the Health-Related Web Site Evaluation Form Emory and then evaluated by five occupational therapists and five speech therapists. The result was subjected to descriptive and quantitative-qualitative treatment, also using the Emory's characteristics and way of analysis. Results: The quality of the website was considered "Adequate" by $81.1 \%$ of the respondents and its content according to age groups was considered "Excellent" by $94.3 \%$ of the respondents. Conclusion: The use of a virtual environment was relevant since it proved to be adequate and to have an excellent content for which it is intended. This result reinforces the idea that technology can benefit therapeutic processes and increase access to this specific treatment.

Keywords: Telemedicine, Occupational Therapy, Child Development, Craniofacial Abnormalities

\section{Introdução}

Reconhecidas pela Organização Mundial de Saúde (OMS) como importante problema de saúde pública, as fissuras labiopalatinas estão entre as malformaçôes de maior incidência, visto que há uma criança nascida a cada dois minutos com fissura no mundo (GARIB et al., 2010).

Para Silva Filho e Freitas (2007), a ocorrência estimada nacional é de 1:650, corroborando com a ocorrência mundial que está entre 1 a cada 700 nascidos (DIXON et al., 2011).

É relevante apontar que embora as fissuras labiopalatinas associadas a quadros sindrômicos tendem a ter a etiologia genética, cromossômica ou exposição teratogênica já definidas ou em definição, as fissuras labiopalatinas isoladas apresentam etiologia multifatorial e complexa (SILVA FILHO; FREITAS, 2007; GARIB et al., 2010).

Em trabalho onde os autores Garib et al. (2010) estudaram a etiologia das más oclusóes é apontado que no Brasil há estimativas de que a maioria dos pacientes com fissuras enquadra-se em classes socioeconômicas menos favorecidas, estes dados foram também encontrados por Cerqueira et al. (2005) ao relatarem a ocorrência de fissuras labiopalatinas na cidade de São José dos Campos - SP, apontando que $73,70 \%$ dos casos investigados, acometeram crianças oriundas dessa classe socioeconômica. Dados parecidos foram encontrados em estudo de Baroneza et al. (2005) ao realizarem trabalho epidemiológico de pessoas com fissuras labiopalatinas em instituiçáo especializada em Londrina - PR.

Essas informaçóes configuram-se como dado importante para proposição de ações de promoção e prevenção em saúde nos diferentes níveis do sistema de assistência, visando a abrangência de toda a população, mesmo aquelas que não são conduzidas precocemente a centros de assistência especializada, por residirem em territórios descentralizados.

Ações como essas podem favorecer o (re) conhecimento dos fatores teratogênicos relacionados às malformaçôes e, em especial, às fissuras labiopalatinas, assim como à viabilização de açóes que otimizem o desenvolvimento desses pacientes nos primeiros anos de vida, cuja cotidianidade fica restrita em muitos momentos a períodos voltados ao tratamento e à hospitalização.

Como referência de assistência especializada e pesquisa na área no Brasil e junto a OMS, o Hospital de Reabilitação de Anomalias Craniofaciais (HRAC/USP), conhecido como Centrinho, em Bauru/SP, configura-se como importante centro na atençáo a pacientes com anomalias craniofaciais e fissuras labiopalatinas, tendo desde sua criaçáo em 1967, 79.000 registros de pacientes atendidos (FREITAS et al., 2012). Atualmente os registros ultrapassam 100.000 pacientes.

Outra característica fundamental da assistência oferecida pelo HRAC/USP aos seus pacientes e familiares é o trabalho interdisciplinar, que, aliado à filosofia do cuidado humanizado estabelecida pelo hospital desde sua criação, aprimora todas suas intervençóes (BASTOS; GARDENAL; GOBO, 2008; FREITAS et al., 2012).

Embora a assistência especializada centralize-se no nível terciário de saúde, é de grande relevância que as práticas e pesquisas desenvolvidas nesse âmbito cheguem também aos outros níveis do sistema.

Considerando que a comunicação em saúde é um potencial recurso na transmissáo de conhecimento e pode promover a capacitação profissional continuada por meio também da realidade virtual que resulta do recente e acelerado desenvolvimento tecnológico, os Programas de Telessaúde podem representar um importante instrumento nesse processo (ZAMBONATO, 2012).

É relevante nesse momento mencionar o que Christante et al. (2003) apontam ao revisar a literatura de avaliaçóes atribuídas à educação médica continuada e a distância. Os autores salientam que diante das dimensóes territoriais de nosso país e da distribuição de renda, o conhecimento fica em sua grande maioria restrito às regióes Sul e Sudeste, 
limitando, por vezes, o acesso por profissionais de outras regióes a eventos científicos, congressos nacionais e internacionais, e, consequentemente, práticas atualizadas.

Diante disso, entende-se que a educação a distância, neste estudo, especificamente a Teleducação, pode fomentar a disseminação do conhecimento e práticas produzidas em diversos centros de pesquisa e ensino às distantes regiốes do país, cujas necessidades são provavelmente mais evidentes.

Conhecendo as características que demarcam o tratamento de crianças com fissuras labiopalatinas e/ou anomalias associadas, por conta de toda a complexidade envolvida no processo de tratamento e reabilitaçáo, com tratamentos longos, ocorrido com periodicidade até a criança atingir a vida adulta e destinado a pessoas de diferentes regiōes do país, necessitando de grandes deslocamentos, justifica-se a atuação da terapia ocupacional (TO) neste contexto e utilização de ferramentas como a Teleducação, visto que estas crianças podem, pelos períodos longos de hospitalização e tratamento ambulatorial, ser privadas de atividades cotidianas que organizam e orientam seu desenvolvimento neuropsicomotor, podendo apresentar prejuízos em seu desenvolvimento.

Cabe ressaltar ainda que, além do foco no bebê e na criança, é importante o olhar para o cuidador. A permanência dos pais em período integral no ambiente hospitalar, sua participação no cuidado e a natureza da relaçáo entre crianças, pais e profissionais, têm desencadeado novas formas de organização da assistência à criança hospitalizada. Nessa perspectiva, o foco é ampliado. Torna-se necessário dirigir o olhar para a família como objeto do cuidado, num processo de produção de relaçóes e intervençôes, para além do atendimento clínico (VIEIRA; DANIELSKI, 2013), pois os pais e/ou responsáveis, durante o período do tratamento das crianças com fissuras labiopalatinas e/ou anomalias craniofaciais, especialmente nos anos iniciais, podem encontrar dificuldades em seus cuidados, devido à insegurança causada pelas características hospitalares e/ou da própria anomalia.

Sendo assim, os serviços de saúde realizam a capacitação da família para que ela assuma alguns cuidados com o bebê, desde o início da hospitalização até a alta hospitalar (NUNES; CUNHA, 2014). Tais cuidados reduzem a ansiedade e aumentam a autoconfiança materna no cuidado domiciliar (PRIDHAM et al., 2006).

Para minimizar esses fatores, torna-se relevante a conduçáo desses casos por profissionais da terapia ocupacional para que possam orientar os pais quanto a estratégias que favoreçam o desenvolvimento da criança em seu cotidiano, transmitindo orientaçóes relacionadas ao brincar, aos manuseios da criança em suas atividades de vida diária (AVD's), como ser segurada no colo, ser vestida e despida, ser amamentada. Isso otimizaria a formação neurológica e contribuiria para a minimização dos riscos que podem prejudicar seu desenvolvimento, pois, assim como as brincadeiras, as atividades de vida diária compóem o repertório de recursos terapêuticos desses profissionais, sendo sua prática orientada para o desenvolvimento dessa área de desempenho ocupacional na vida do sujeito (AMERICAN..., 2014).

Neste contexto ressalta-se o papel do profissional da TO na equipe de assistência, pois, como aponta a American Occupational Therapy Association (2014), a TO tem em sua estrutura de atuação as ocupaçôes, que são caracterizadas pelas atividades de vida diária (AVD's), atividades instrumentais de vida diária (AIVD's), descanso e sono, educação, trabalho, brincar, lazer e participação social. Estas ocupaçóes ocorrem mediadas por fatores relacionadas ao cliente como valores, crenças, espiritualidade, funções e estruturas do corpo. Considera-se ainda que, para que elas ocorram de forma organizada e adequada, as habilidades e padróes de desempenho estejam íntegros e que aconteçam em contextos e ambientes favoráveis a esse desenvolvimento.

Considerando isso, cabe ao terapeuta ocupacional, como integrante da equipe multidisciplinar e profissional na área da saúde, fomentar o desenvolvimento de programas e práticas educativas que possibilitem a promoção, a prevenção e a recuperação neste âmbito.

Para tal considera-se a utilização da telessaúde na vertente da Teleducação na transmissão das práticas desenvolvidas na assistência terapêutica junto a pais e/ou responsáveis de crianças com fissuras labiopalatinas. Considerando isto, o objetivo do estudo foi elaborar e analisar um ambiente virtual de aprendizagem do desenvolvimento infantil de crianças de 0 a 2 anos de idade.

\section{Método}

Trata-se de uma pesquisa aplicada, de caráter quanti-qualitativa, do tipo descritiva que recebeu aprovação do Comitê de Ética em Pesquisa do HRAC/USP sob parecer de $n^{\circ} 637.576$ e CAEE 28274814.4.0000.5441.

A pesquisa é aplicada, pois resulta no desenvolvimento e avaliação de um ambiente virtual e, como apontam Parra Filho e Santos (1998), tem como objetivo a criação de novos produtos. 
Caracteriza-se também como uma pesquisa descritiva, visto que tem a proposição de observar, registrar, analisar, classificar e interpretar os fatos sem que o pesquisador interfira, descrevendo as características de determinadas situaçóes, populaçóes ou, entáo, o estabelecimento de relaçóes entre as variáveis (CHIZZOTTI, 1991).

\subsection{Procedimentos para coleta de dados}

Inicialmente foi criado um ambiente virtual (site) fundamentado no desenvolvimento infantil e suas implicaçóes na prática terapêutica mediante parceria estabelecida entre terapeutas ocupacionais e fonoaudiólogo com profissionais e pesquisadores $\mathrm{da}$ área de Ciência da Computação (CI) da Universidade Sagrado Coração - Bauru, interior de São Paulo.

Para viabilizaçáo do site foi adotado um framework, que se caracteriza como uma estrutura base gratuita utilizada na construção de layouts responsivos para websites e mobiles (GITHUB..., 2016).

$\mathrm{O}$ ambiente virtual foi desenvolvido também utilizando tecnologias como as Linguagens de Programação PHP e AIML (Artificial Intelligence Markup Language), o servidor de banco de dados MySQL, e técnicas de Inteligência Artificial.

O termo PHP é um acrônimo recursivo para "PHP: Hypertext Preprocessor", sendo considerado um interpretador. Entende-se como interpretador um programa que lê um arquivo contendo o código a ser executado e age imediatamente sobre ele. O código deste arquivo é chamado de código-fonte. Em geral esse código pode ser lido e entendido por uma pessoa, gerando uma linguagem interpretada (BUYENS, 2002). A linguagem de programaçáo PHP foi obtida gratuitamente através do seu site oficial (PHP..., 2016).

O MySQL é um Sistema Gerenciador de Banco de Dados (SGBD), que suporta várias linguagens de programação. É caracterizado por Buyens (2002) como um software de banco de dados que suporta a linguagem de consulta de banco SQL (Structured Query Language) que é um padrão de comunicaçáo com bancos de dados de qualquer tipo, náo importando os métodos subjacentes de escrever e ler os dados.

A AIML é uma linguagem baseada em XML (Extensible Markup Language) que trabalha com um conjunto de duplas, as quais sáo compostas por uma pergunta que é feita pelo usuário e uma resposta que é retornada pelo agente conversacional (OLIVEIRA, 2010).
Para Macedo (2012, p. 49) a linguagem AIML "[...] é capaz de representar e relacionar expressóes em linguagem natural, permitindo a criação de motores robóticos capazes de manter um diálogo simples".

Já a Inteligência Artificial é um tipo de inteligência produzida pelo homem para dotar as máquinas de algum tipo de habilidade simulando a inteligência humana (FERNANDES, 2005).

De acordo com Cunha e Ribeiro (1987), a Inteligência Artificial é considerada uma parte da computação que busca tornar uma máquina mais inteligente, com a utilização de algoritmos e técnicas representando situaçóes consideradas especificamente como humanas.

Concomitantemente à construção e programação das ferramentas do ambiente virtual, os conteúdos que o compuseram foram fomentados pela pesquisadora a partir de levantamentos bibliográficos de técnicas e teorias aplicadas na área de desenvolvimento infantil, assim como no caso das imagens, vídeos e áudios utilizados, que foram fabricados e/ou correspondem ao arquivo pessoal da autora.

Como referencias teóricas para composição do conteúdo do ambiente virtual, foram utilizados livros, artigos e teses, do período de 1984 até 2015, que versam sobre anomalias craniofaciais, fissuras labiopalatinas, desenvolvimento infantil, saúde da criança, terapia ocupacional e fonoaudiologia, como os trabalhos de Trindade e Silva Filho (2007), Altmann (2005), Béziers e Hunsinger (1994), Liddle e Yorke (2006), Brandão (1984), Cavalcanti e Galvão (2007), Estivill e Arboledas (2014), Case-Smith e O'Brien (2010), Bee (2003), Piaget (1967, 1971, 1991), Gesell e Amatruda (2000). Estes materiais fundamentaram os textos, conteúdos dos vídeos e demais ferramentas do site.

Para a elaboração dos vídeos foram convidados os responsáveis de crianças de 0 a 2 anos de idade para participarem de filmagens. Cientes quanto à veiculaçáo das imagens das crianças sob sua responsabilidade a um site resultante da tese de doutorado, os responsáveis assinaram o formulário de permissão para uso de registros para fins científicos. Esses responsáveis foram às mães de crianças com e sem fissuras labiopalatinas e anomalias craniofaciais, que tiveram seus filhos filmados e/ou fotografados em momentos de atendimentos terapêuticos ocupacionais no HRAC/USP ou em encontros ocorridos na USC agendados com antecedência diretamente pela autora do projeto, que também é docente na referida Instituição de Ensino.

As filmagens e imagens constituíram-se de materiais que ilustram e orientam o que é esperado da criança em fases de seu desenvolvimento, considerando os 
aspectos motores, afetivo-social, da linguagem, cognitivos, aspectos relacionados às atividades do dia a dia e do brincar.

Além das filmagens realizadas com as crianças, foram construídos vídeos de orientaçóes relacionadas ao tema com profissionais envolvidos no projeto, sendo estes dois terapeutas ocupacionais e um fonoaudiólogo.

Uma ferramenta que compóe o ambiente foi criada exclusivamente para este trabalho - o agente conversacional $\mathrm{TeO}$, que se trata de um sistema de Processamento de Linguagem Natural (PLN - chatterbot) em AIML.

O PLN versa de forma computacional os aspectos contidos na comunicação humana, como sons, palavras, sentenças e discursos, considerando formatos e referências, estruturas e significados, contextos e usos. Em sentido bem amplo, o PLN busca fazer com que o computador se comunique em linguagem humana (GONZALEZ; LIMA, 2003).

De acordo com Levine, Drang e Edelson (1988, p. 25) o objetivo do PLN

[...] é permitir que o usuário 'fale' com o computador em linguagem humana, como o inglês ou português, e fazer com que o computador responda na mesma língua.

O Processamento de Linguagem Natural, para Siqueira (2011), visa simular as capacidades humanas de comunicação e interpretação, também chamadas Linguagens Naturais, de forma computacional, utilizando, para esse fim, técnicas de representaçâo de conhecimento. O uso do PLN é primordial para diversas áreas do conhecimento humano e possui importantes aplicabilidades de cunho social, econômico e educacional, sendo neste projeto aplicado à área da saúde.

Para a proposição do $\mathrm{TeO}$, foram utilizadas uma base de conhecimento padrão contendo saudações, cumprimentos, armazenamento de nome ou dos tópicos da base de conhecimento específico, tratamentos de sentenças desconhecidas, entre outros, e uma outra base, específica da área da saúde, com informações sobre o desenvolvimento infantil.

Após a finalização da elaboração do ambiente virtual, participantes da pesquisa avaliaram-no.

\subsection{Participantes da pesquisa}

Posteriormente ao momento de desenvolvimento do ambiente virtual, o mesmo foi submetido a 10 avaliadores, cinco profissionais da terapia ocupacional e cinco profissionais da fonoaudiologia, com formação e experiência mínima de um ano na área, os quais avaliaram o nível e adequação dos conteúdos em face dos objetivos da pesquisa.

Ressalta-se que anteriormente aos momentos de avaliação do ambiente foi enviada uma carta convite aos participantes esclarecendo-os sobre os objetivos e metodologia do trabalho. Como finalização desses procedimentos, fizeram parte da amostra, avaliadores que aceitaram participar do estudo e que registraram aceite do Termo de Consentimento Livre e Esclarecido no próprio sítio eletrônico.

\subsection{Instrumento de coleta de dados}

Para avaliação foi utilizado o questionário adaptado do Health-Related Web Site Evolutation Form Emory (UNIVERSITY..., 1998). O instrumento Emory é composto por 36 questões que são divididas nas escalas: conteúdo, precisão, autores, atualizações, público, navegação, links, estrutura.

As opçóes de resposta a cada item das escalas dimensionadas acima são identificadas como "concordo" atribuindo-se dois pontos, "discordo" atribuindo um ponto e para alguns itens a opção de resposta corresponde a "não se aplica", na qual é atribuído zero ponto. Ao final da aplicação do instrumento, foram realizados os cálculos do total de pontos obtidos, multiplicando a quantidade de avaliadores ao valor atribuído as respostas, dois para "concordo" e um para "discordo" e o cálculo do número de pontos possíveis.

Para encontrar o resultado final em porcentagem, foi utilizada a fórmula descrita no questionário Emory, sendo a porcentagem de pontos totais possíveis o resultado da multiplicação da pontuação total obtida por 100, divido pela pontuação total possível, como demonstrado abaixo.

$$
\frac{\text { Pontuação total obtida } \times 100}{\text { Pontuaçáo total possível }}=\begin{gathered}
\text { Porcentagem de } \\
\begin{array}{c}
\text { pontos totais } \\
\text { possiveis }
\end{array}
\end{gathered}
$$

A porcentagem obtida representa a qualidade do material virtual, sendo que se o resultado atinge pelo menos $90 \%$ dos pontos o caracteriza como excelente, caso atinja pelo menos $75 \%$, o ambiente é avaliado como adequado e menos de 75\%, como pobre.

A descrição desta avaliação é apresentada na Tabela 1.

\subsection{Forma de análise dos dados}

A partir da coleta dos dados obtidos com o Emory, os mesmos foram submetidos à análise descritiva e tratamento quanti-qualitativo dos resultados de 
acordo com as características e forma de análise proposta no próprio instrumento.

\section{Resultados}

O processo que envolveu este trabalho permite a apresentaçáo dos resultados quanto aos passos dados para sua elaboração e os resultados do processo que envolve a avaliaçáo do site pelos participantes da pesquisa.

Inicialmente, foi realizada a produção dos conteúdos teóricos para o site, que se constituíram de textos em linguagem simplificada e acessível ao perfil da clientela para a qual se destina o trabalho (pais e responsáveis de crianças), criados também o logo, vídeos e imagens que integram o visual do site.

Para criação do logo, inicialmente houve a ideação do nome. Considerando que o trabalho é proveniente dos estudos de um profissional da área de terapia ocupacional (TO), vislumbrou-se demarcar essa referência no nome do site e, associado ao processo de desenvolvimento infantil, pensou-se no nome TO Crescendo (Figura 1), no qual se entende "Estou Crescendo". Além da veiculação do TO no nome do site, ele foi associado aos diversos termos adotados no layout. Paralelamente a isso foram delimitadas as abas e ferramentas que compõem o site e os seus respectivos conteúdos. As abas e ferramentas disponíveis no ambiente são: parte superior (Figura 1), home (denominada como "TO Crescendo"), "TO Desenvolvendo", "Acompanhe seu Bebê", "Fale com o TeO", "Mais", aba na qual há itens referentes à download, kinks de interesse, notícias, referência bibliográficas, glossário, conheça os autores. Na parte inferior estáo os itens "Autores", "Dúvidas" e "Avalie o Site".

$\mathrm{Na}$ home "TO Crescendo" do site, é realizada uma apresentação do espaço, indicando qual é seu objetivo, a quem se destina e por quem foi idealizado.

Tabela 1. Pontuação e classificação do ambiente virtual de acordo com o questionário Emory.

\begin{tabular}{cl}
\hline \multicolumn{1}{c}{ Avaliação } & \multicolumn{1}{c}{ Descrição } \\
\hline \multirow{2}{*}{ Excelente - pelo menos 90\% } & $\begin{array}{l}\text { Este ambiente é uma fonte excelente de informação da saúde. Os consumidores } \\
\text { poderão alcançar e compreender facilmente a informação contida neste local. } \\
\text { Não hesite em recomendar este site aos seus clientes. }\end{array}$ \\
\hline & $\begin{array}{l}\text { Este ambiente fornece informações relevantes e pode ser navegado sem muitos } \\
\text { problemas, no entanto, pode não ser o melhor ambiente virtual disponível. } \\
\text { Adequado - pelo menos 75\% } \\
\text { Se outra fonte de informação não puder ser localizada, este recurso fornecerá } \\
\text { boa informação para o cliente. Deve ser tomada cautela quando conversar com } \\
\text { seu cliente sobre a informação encontrada no ambiente virtual e a informação } \\
\text { que realmente é necessária. }\end{array}$ \\
\hline & $\begin{array}{l}\text { Este ambiente virtual não deve ser recomendado aos seus clientes. A validade e } \\
\text { a confiabilidade da informação não podem ser confirmadas. Toda a informação } \\
\text { do recurso pode não ser acessível. Procure outro ambiente virtual para impedir } \\
\text { que a informação falsa ou parcial seja lida. }\end{array}$ \\
\hline
\end{tabular}

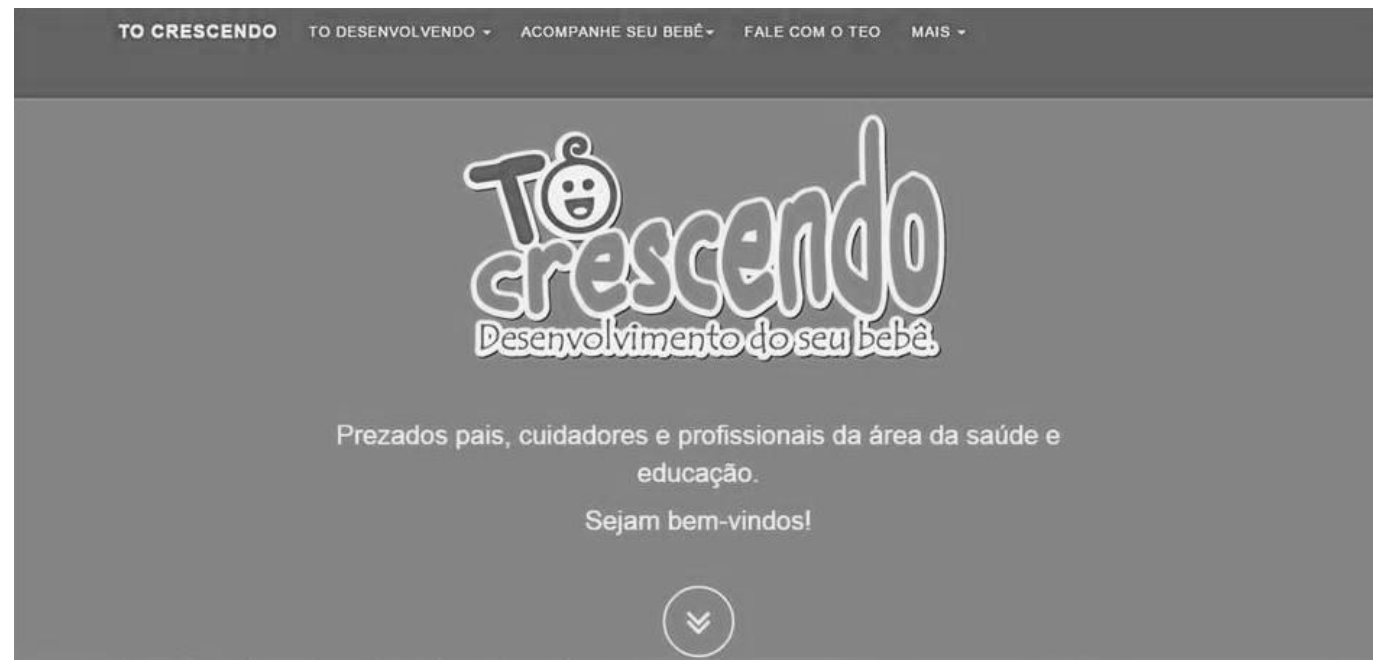

Figura 1. Logo e abas na parte superior da home do site. 
$\mathrm{Na}$ aba "TO Desenvolvendo" concentram-se informaçôes referentes ao desenvolvimento infantil, de 0 a 2 anos de idade, divididos nos períodos de 0 a 3 meses, 3 a 6 meses, 6 a 9 meses, 9 a 12 meses, 12 a 18 meses e 18 a 24 meses. Apresenta ainda itens com informaçôes relacionadas ao desenvolvimento da preensão e recursos adaptados. Nesta aba, a palavra "TO" vem veiculada com as idades, apresentando-se como TO com 0 a 3 meses e assim sucessivamente. Os aspectos apresentados em cada idade do bebê, relacionados aos aspectos motores, cognitivos, afetivo-sociais, às atividades do dia a dia, ao brincar e falar, foram denominados como "TO Movimentando", "TO Pensando", “TO Interagindo", "TO Fazendo", "TO Brincado" e "TO Falando", respectivamente.

O "Acompanhe seu bebê" é uma ferramenta na qual o usuário do ambiente virtual poderá, mediante um checklist respondido com sim ou não, identificar quais os comportamentos presentes ou ausentes no desenvolvimento da sua criança e/ou filho. Esse instrumento foi baseado em diferentes escalas de avaliação de desenvolvimento infantil, como Denver II, de Frankenburg et al. (1992), Werner (1994), o Inventário Portage operacionalizado de Williams e Aiello (2001), a escala para avaliação e acompanhamento padronizada de Pinto, Vilanova e Vieira (1997), a Escala ELM - Early language Milestone Scale de Coplan, Gleason e Ryan (1982) e avaliação do desenvolvimento neuropsicológico de Gesell e Amatruda (2000), abordando aspectos relacionados ao desenvolvimento motor, afetivo-social, da linguagem e cognitivo. A partir da seleção dos itens, o recurso dá um feedback ao usuário do ambiente, orientando-o a atentar-se ao desenvolvimento de alguns aspectos de sua criança e dirigir-se à aba "TO Desenvolvendo" para conhecer diferentes formas de estímulos que poderão auxiliar na promoção do desenvolvimento da criança em questão.
Essa ferramenta foi construída utilizando-se a programação em PHP. A partir dessa programação e definição de categorias como desenvolvimento motor, afetivo-social, da linguagem e cognitivo, o sistema tornou-se capaz de rastrear as áreas do desenvolvimento menos desenvolvidas no bebê, cujo responsável responde à ferramenta. Diante disso, o sistema gera uma resposta enfatizando a orientação específica ao usuário, indicando em que categoria a criança precisa de maiores estímulos e orientando-o a buscar informações nas abas do site.

A ferramenta "Fale com o TeO", o chatterbot, construído para este estudo pode caracterizar-se como um robô e foi vinculado a uma aparência e nomeado como TeO (Figura 2).

A base de conhecimento específica foi desenvolvida por meio de perguntas e respostas e, para que o chatterbot fizesse um melhor reconhecimento da língua portuguesa, foram realizadas adaptaçóes referentes à acentuação ortográfica e, para orientar melhor o usuário do robô de conversação, foi adicionado um campo no qual se sugerem quais são as perguntas mais frequentemente feitas pelos usuários e, para que as sugestóes não fossem repetidas em todos os acessos, elas foram armazenadas em um banco de dados e selecionadas de forma aleatória. O sistema foi testado de duas maneiras, por meio do Teste Funcional e por simulaçóes de conversas feitas para verificar cada funcionalidade presente no chatterbot e o mesmo apresentou um desempenho satisfatório com os temas mais abordados pelos pacientes. A Figura 2 ilustra também a simulação de uma conversa com o $\mathrm{TeO}$.

Como já mencionado, na parte inferior da home do site estão disponíveis os ícones "Autores", no qual são apresentados os autores responsáveis pelo trabalho, "Dúvida", no qual o usuário encontra outro

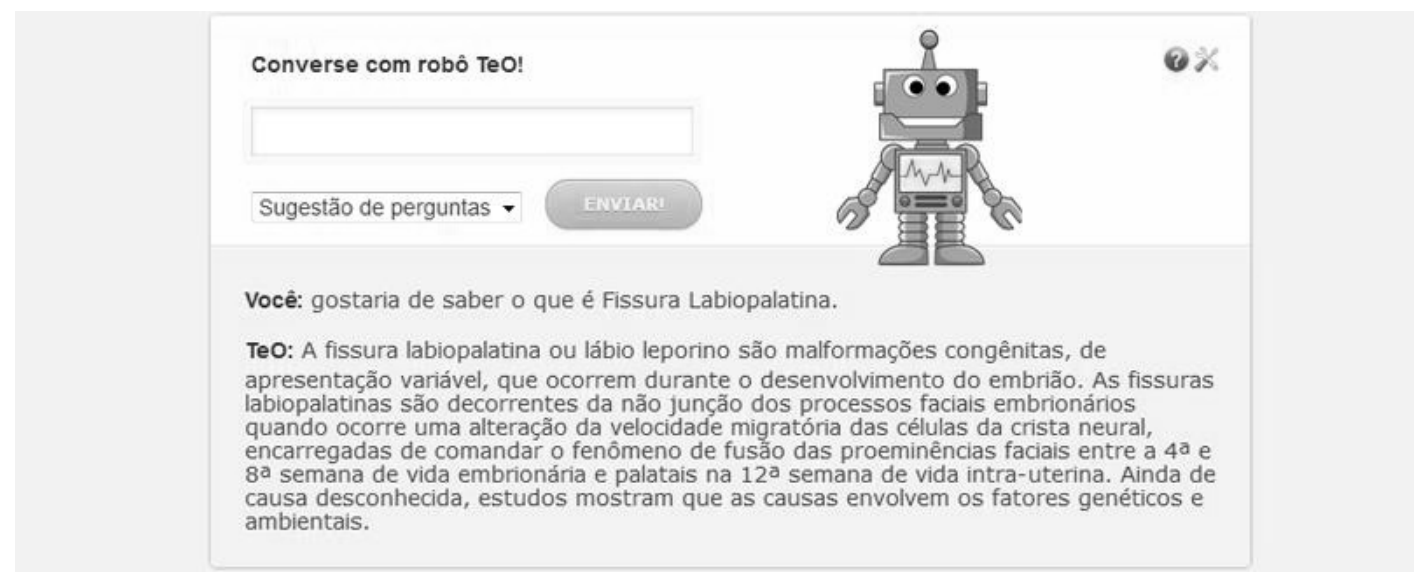

Figura 2. Simulação de conversa com o TeO. 
caminho para acessar o chatterbot $\mathrm{TeO}$ e "Avalie o site", que constitui uma ferramenta para que todos os usuários do site, quando em domínio público, possam avaliá-lo.

Ressalta-se que todo conteúdo que compóe o site busca atingir pais e responsáveis de crianças com e sem fissuras labiopalatinas e anomalias craniofaciais. Sendo assim, justifica-se que os conteúdos abordados contemplaram padróes de desenvolvimento e comportamentos típicos, assim como orientaçóes específicas à clientela com fissuras labiopalatinas e anomalias relacionadas.

Após o processo de construção e implementaçáo do site, o mesmo passou pela avaliaçáo, na qual tiveram como participantes dez profissionais, sendo eles cinco terapeutas ocupacionais e cinco fonoaudiólogos. Entre os profissionais de terapia ocupacional um tem o título de doutor, três são mestres e um, especialista. O tempo de formação e atuação na área corresponde a dois profissionais atuantes na área por mais de dez anos, um profissional com tempo de cinco a dez anos e dois profissionais de um a cinco anos de atuação na área de desenvolvimento infantil.

Dos profissionais de fonoaudiologia participantes, um é doutor, três são mestres e um é graduado, sendo três deles atuantes na área de desenvolvimento infantil por mais de dez anos, um deles no período entre cinco e dez anos e um atuante no tempo de um a cinco anos.

Como resultado das avaliaçóes realizadas pelos profissionais quanto a representação de qualidade do material virtual, consideraram-se as oito escalas do questionário Emory, permitindo a análise dos resultados considerando os itens: conteúdo, precisão, autoria, atualizaçôes, público, navegação, links externos e estrutura do site. Estas escalas apresentam-se divididas entre os números de questóes do instrumento Emory, conforme é apresentado na Tabela 2.

Da mesma forma, foi realizada a pontuação geral do questionário para os itens "concordo", "discordo" e "não se aplica", desconsiderando as escalas separadamente. Desta maneira, a pontuação obtida foi de 584, sendo que a pontuação total possível é de 720 , considerando o número de participantes. De acordo com a análise proposta, a porcentagem correspondente foi de $81,1 \%$, que indica a qualidade do site como Adequado.

Para descrever os resultados do questionário quanto aos conteúdos de cada página destinada às faixas etárias que o site contempla, também foi adotada a análise adaptada pela pontuação proposta pelo questionário Emory (Figura 2), sendo consideradas as opçóes de resposta a cada
Tabela 2. Pontuação do questionário Emory, distribuída por escalas de avaliação.

\begin{tabular}{ccc}
\hline Questões & Escala Emory & Emory \% \\
\hline 1 a 6 & Conteúdo & 90,8 \\
7 a 9 & Precisão & 61,6 \\
10 a 12 & Autoria & 88,3 \\
13 a 14 & Atualizações & 82,5 \\
15 a 18 & Público & 91,2 \\
19 a 24 & Navegação & 71,6 \\
25 a 30 & Links externos & 96,6 \\
31 a 36 & Estrutura & 64,1 \\
\hline
\end{tabular}

Pontuação maior ou igual a $90 \%=$ qualidade excelente; Pontuação entre $75 \%$ e $89 \%$ = qualidade adequada; Pontuação menor que $75 \%=$ qualidade pobre.

Tabela 3. Pontuação do questionário Emory, distribuída pelas páginas do site.

\begin{tabular}{cc}
\hline Páginas do Site & Emory \% \\
\hline 0 a 3 meses & 96 \\
3 a 6 meses & 94 \\
6 a 9 meses & 94 \\
9 a 12 meses & 94 \\
12 a 18 meses & 94 \\
18 a 24 meses & 94
\end{tabular}

Pontuação maior ou igual a $90 \%=$ qualidade excelente; Pontuação entre $75 \%$ e $89 \%$ = qualidade adequada; Pontuação menor que $75 \%$ = qualidade pobre.

item das escalas dimensionadas como "muito bom", atribuindo-se cinco pontos, "bom", atribuindo-se quatro pontos, "regular", atribuindo-se três pontos, "ruim", atribuindo-se dois pontos, "muito ruim", um ponto, e para alguns itens a opção de resposta corresponde a "não se aplica", à qual foi atribuído zero ponto.

$\mathrm{Na}$ Tabela 3 são apresentadas as porcentagens obtidas no questionário quanto a qualidade dos conteúdos por faixa etária nas páginas do site.

Considerando a pontuação geral do questionário para os itens apresentados na Tabela 2, que foi de 283 , sendo que a pontuação total possível é de 300, considerando o número de participantes, a porcentagem correspondente à avaliação do conteúdo pelos participantes quanto às faixas etárias contempladas no trabalho foi de $94,3 \%$, que indica a qualidade deste conteúdo como excelente.

\section{Discussão}

A proposiçấo de um ambiente virtual idealizado por um profissional da terapia ocupacional voltado a pais e/ou responsáveis de crianças baseado na temática do desenvolvimento infantil e assistência a 
crianças com fissura labiopalatina, pode ser estendido tanto às crianças com anomalias craniofaciais associadas como às sem alteraçôes, atrela-se ao atual desenvolvimento tecnológico e suscita avanços que conduzem importantes benefícios para os projetos da área da saúde, que se multiplicam e favorecem o compartilhamento de conhecimentos e a melhor qualificaçấo da assistência prestada na área.

Para tal, este trabalho apoiou-se nas propostas dos programas de Telessaúde que se constitui em uma forma de transmissão de serviços ou informaçóes relacionados com a saúde por meio de tecnologias de uma infraestrutura de telecomunicaçóes, incluindo, segundo a OMS (WORLD..., 2010), prestação de serviços de saúde em casos nos quais a distância é um fator crítico, possibilitando a realização de serviços clínicos à distância (diagnóstico, tratamento e prevenção de doenças) e elementos não clínicos do sistema de saúde, como pesquisa, avaliação e a educação.

Considerando a relevante contribuição da Telessaúde e Teleducação nas práticas de saúde, a elaboração de ambientes virtuais de aprendizagem, como este trabalho, podem representar um avanço nas metodologias de assistência em saúde, como se verifica no trabalho de Picolini et al. (2013), no qual elaboraram um ambiente virtual de aprendizagem sobre Síndromes Genéticas e apontam a Telessaúde como eficiente estratégia utilizada na oferta de serviços de saúde, sendo esta fomentada por meio de tecnologias de informação e comunicação a situaçóes em que a distância física e/ou temporal pode ser obstáculo ao acesso à informaçáo voltada a saúde. Neste mesmo contexto, este trabalho buscou como Costa et al. (2013), a partir de orientaçóes especializadas, tornar-se um meio de comunicaçáo eficaz para a promoção da saúde, uma vez que favorece a troca de conhecimentos, náo dizendo respeito ao simples lançar de informaçóes, a pais e/ou responsáveis de crianças com fissura labiopalatinas e/ou anomalias craniofacias que por vezes são oriundos de territórios nacionais distantes do centro de reabilitação especializado.

Além da proposição de uma metodologia contemporânea para a assistência em saúde, verifica-se que o recurso virtual pode atingir um maior número de pessoas, otimizando a chegada de informaçôes especializadas a públicos que se limitam à precariedade da assistência ofertada no seu local de procedência, como é o caso de muitas famílias de crianças assistidas atualmente no HRAC/USP, que é um serviço conveniado com o SUS, especializado no atendimento de pessoas com anomalias craniofaciais e síndromes associadas, no qual o tratamento envolve a ação de uma equipe interdisciplinar e demanda vários anos de intervençấo e cuidados, e as dificuldades enfrentadas pelas famílias vão desde questóes financeiras e geográficas a familiares para o acesso a esse tratamento (GRACIANO et al., 2015).

Isso é evidenciado por Melo et al. (2010) que, ao utilizarem a videoconferência para capacitar agentes comunitários de saúde sobre a saúde auditiva, registram eficácia na formação de profissionais em áreas descentralizadas e carentes, visto que, a partir da utilização dessas ferramentas, os profissionais tornam-se multiplicadores da assistência especializada e promovem não só a saúde, mas também incentivam e monitoram as famílias em relação ao cuidado prestado a criança, podendo otimizar a identificação precoce de problemas relacionados.

Percebe-se que sistematização do conteúdo a ser disponibilizado nestes ambientes e responsividade do recurso tecnológico utilizado são fundamentais para a garantia da transmissão de um conhecimento adequado ao público alvo, entretanto entende-se que devem ser utilizados de forma complementar a métodos presenciais, a fim de atingir os resultados esperados na assistência.

Wakeford et al. (2005), ao discorrerem sobre o posicionamento da AOTA diante da utilização das tecnologias nas assistências terapêuticas ocupacionais, mencionam que a apropriação dessa ferramenta como mais um recurso terapêutico na área, embora ofereça muitas novas oportunidades na prestação de serviços, ainda está se consolidando, no entanto tem se mostrado eficaz em diferentes âmbitos, seja ele no processo de avaliação, intervenção, consulta, educação e supervisão de estudantes ou outros profissionais.

Cason (2012) menciona que as aplicaçôes da Telessaúde na TO voltam-se a programas que visam o desenvolvimento de habilidades, que incorporem tecnologias assistivas e técnicas adaptadas, criem possibilidades que incentivem rotinas pautadas na promoção em saúde, assim como modificações no trabalho, casa, escola e outros ambientes, tornando-os mais eficientes ao desempenho ocupacional do sujeito envolvido na assistência.

A autora ainda descreve que, quando voltada à populaçáo infantil, a TO, por meio da telessaúde, promove o desenvolvimento de competências comuns à idade e melhora a qualidade de vida de bebês e crianças com atraso no desenvolvimento e deficiências.

Como é possível identificar, atualmente há a participaçáo de terapeutas ocupacionais em ações que envolvem a Telessaúde, mas ainda assim são 
poucos os estudos que envolvem a temática e, quando se fala no Brasil, verifica-se que telessaúde e telemedicina já estão mais estruturadas, estando mais voltadas para área médica na atenção básica e trocas de informaçôes entre equipes especializadas e não especializadas.

Verificou-se ainda como resultado deste trabalho que, ao ser submetido à avaliação de terapeutas ocupacionais e fonoaudiólogos, foi julgado um recurso adequado para os fins a qual se destina, sendo ainda considerado como excelente e adequado à maioria dos itens avaliados pelo instrumento Emory. Esses achados indicam que embora o material tenha uma boa qualidade, o mesmo deve ser cuidadosamente organizado para disponibilização e que a avaliação contínua para revisão e atualização dos dados fornecidos neste ambiente virtual é imprescindível para que seu objetivo seja alcançado.

Quanto à qualidade dos conteúdos por faixa etária nas páginas do site, verificou-se que o mesmo fora considerado excelente. A partir disso identifica-se que o ambiente virtual, quando sistematizado de forma criteriosa, poderá contribuir para ampliaçáo de meios para acesso às informaçóes especializadas da terapia ocupacional voltadas ao desenvolvimento infantil de crianças de zero a dois anos de idade.

Considerando isso, e partir do desenvolvimento deste trabalhado, apontam-se como principais desafios da ampliação e consolidação da assistência da TO prestada neste âmbito, a articulação bem-sucedida de profissionais da saúde e da tecnologia. Desta forma, as disciplinas deverão se aproximar do conhecimento específico da outra área e buscar maior responsividade e funcionalidade na elaboraçáo e implementação da metodologia, pois como foi visto a partir da avaliação do ambiente, este é considerado adequado ao fim ao qual se destina. Isso posto, espera-se que o material possa ser aprimorado futuramente e passe a ser utilizado como mais um recurso para promoçáo, prevenção e recuperação do desenvolvimento infantil. Entende-se que a proposta multidisciplinar apresentada, a qual contou com a informática como ferramenta de apoio na prática terapêutica ocupacional, poderá promover uma maior interação entre familiares e profissionais da área e, consequentemente, possibilitar melhora dos resultados apresentados nos tratamentos.

\section{Conclusão}

$\mathrm{O}$ ambiente virtual de aprendizagem elaborado foi analisado positivamente por profissionais especializados, o que confere alta aplicabilidade ao recurso, pois atende aos critérios de um ambiente virtual de aprendizado, como conteúdo, precisão, navegaçáo e estrutura.

A partir do desenvolvimento do presente estudo pode verificar-se que a proposição de ambientes virtuais voltados à pais e/ou responsáveis de crianças com anomalias craniofaciais sobre a temática do desenvolvimento é relevante, visto que se apoia em conteúdos e estratégias que atualmente concentram-se em populações distintas, sendo essas, por vezes, pessoas que têm a possibilidade de acessar apenas presencialmente centros de assistência em saúde voltados a essas demandas e que correspondem ainda à minoria da populaçáo. Entretanto, verificou-se ainda que, mesmo que se tenha consciência e se busque um recurso acessível a todos, a linguagem e ferramentas utilizadas nos ambientes virtuais, por vezes, não se ajustam às reais necessidades do público alvo. A partir disso questiona-se se a responsividade e funcionalidade desses ambientes têm sido suficientes, dessa forma, e identificou-se necessária uma análise pormenorizada antes de chegar ao público ao qual se destinam.

Para tal, percebe-se que é imprescindível a articulação, o trabalho em conjunto e afinado de profissionais da área da saúde e da tecnologia. As relaçôes estabelecidas entre as partes serão preditoras do sucesso do ambiente virtual proposto, pois há necessidade da apropriação de saberes disciplinares e uma aplicabilidade destes de forma interdisciplinar.

Considerando isso, entende-se que este fator constitui-se no principal desafio, visto que os conhecimentos são distintos e a própria linguagem técnica das áreas pode ser obstáculo para a comunicação efetiva entre os envolvidos e exequibilidade da proposta de uma forma mais apropriada. Quanto à contribuição da terapia ocupacional, foi identificado que embora existam trabalhos que versam sobre o desenvolvimento infantil e que também estão associados à ambientes virtuais e recursos tecnológicos, nenhum se propôs a direcionar as suas orientaçôes à assistência de crianças com fissura labiopalatina e/ou anomalias craniofaciais, confirmando a relevância do presente estudo.

\section{Referências}

ALTMANN, E. Fissuras Labiopalatinas. Barueri: Pró Fono, 2005.

AMERICAN OCCUPATIONAL THERAPY ASSOCIATION - AOTA. Occupational therapy practice framework: domain e process. American Journal of $\mathrm{Oc}$ cupational Therapy, Bethesda, v. 68, p. S1-S48, 2014. Suplemento 1. 
BARONEZA, J. E. et al. Dados epidemiológicos de portadores de fissuras labiopalatinas de uma instituição especializada de Londrina, Estado Estado do Paraná. Acta Scientiarum. Health Science, Maringá, v. 27, n. 1, p. 31-35, 2005.

BASTOS, P. R. H. O.; GARDENAL, M.; BOGO, D. O. Ajustamento social dos portadores de anomalias craniofaciais e a práxis Humanista (revisão). Arquivos Internacionais de Otorrinolaringologia, São Paulo, v. 12, n. 2, p. 280-288, 2008.

BEE, H. A criança em desenvolvimento. Porto Alegre: Artmed, 2003.

BÉZIERS, M. M.; HUNSINGER, Y. O bebê e a coordenação motora: os gestos apropriados para lidar com a criança. São Paulo: Summus, 1994.

BRANDĀO, J. S. Desenvolvimento psicomotor da mão. Rio de Janeiro: Enelivros, 1984.

BUYENS, J. Aprendendo MySQL e PHP. São Paulo: Makron Books, 2002.

CASE-SMITH, J. O.; BRIEN, J. C. Occupational therapy for children. Maryland Heights: Mosby/Elsevier, 2010.

CASON, J. Telehealth opportunitiesin occupational therapy through the affordable care act. American Journal of Occupational Therapy, Rockville, v. 66, n. 2, p. 131-136, 2012.

CAVALCANTI, A.; GALVÃO, C. Terapia Ocupacional: fundamentação e prática. Rio de Janeiro: Guanabara Koogan, 2007.

CERQUEIRA, M. N. et al. Ocorrência de fissuras labiopalatinas na cidade de São José dos Campos - SP. Revista Brasileira de Epidemiologi, São Paulo, v. 8, n. 2, p. 161166, 2005.

CHIZZOTTI, A. Pesquisa em ciências humanas e sociais. São Paulo: Cortez, 1991.

CHRISTANTE, L. et al. O papel do ensino a distância na educação médica continuada: uma análise crítica. $R e-$ vista da Associação Médica Brasileira, São Paulo, v. 49, n. 3, p. 326-329, 2003.

COPLAN, J.; GLEASON, J. R.; RYAN, R. Validation of an early language milestone scale in a high risk population. Pediatrics,Springfield, v.70, p. 677-683, 1982.

COSTA, P. B. et al. Construção e validação de manual educativo para a promoção do aleitamento materno. Rev Rene, v. 14, n. 6, p. 1160-1167, 2013.

CUNHA, H.; RIBEIRO, S. Introdução aos sistemas especialistas. Rio de Janeiro: LTC, 1987.

DIXON, M. J. et al. Cleft lip and palate: understanding genetic and environmental influences. Nature Reviews Genetics, London, v. 12, n. 3, p. 167-178, 2011.

FERNANDES, A. M. R. Inteligência artificial: noções gerais. Florianópolis: Visual Books, 2005.
FRANKENBURG, W. K. et al. The Denver II: a major revision and restandardization of the Denver Developmental Screening Test. Pediatrics,Springfield, v.89, n.1, p.91-97, 1992.

FREITAS, J. A. S. et al. Rehabilitative treatment of cleft lip and palate: experience of the Hospital for Rehabilitation of Craniofacial Anomalies/USP (HRAC/USP) part 1: overall aspects. Journal of Applied Oral Science, Bauru, v. 20, n. 1, p. 9-15, 2012.

GARIB, D. G. et al. Etiologias das más oclusões: perspectiva clínica (parte III) - fissuras labiopalatinas. Revista Clinica de Ortodontia Dental Press, Maringá, v. 9, n. 4, p. 30-36, 2010.

GESELL, A.; AMATRUDA, C. S. Diagnóstico do desenvolvimento: avaliação do desenvolvimento neuropsicológico no lactente e na criança pequena: o normal e o patológico. Rio de Janeiro: Atheneu, 2000.

GITHUB. Bootstrap is the most popular HTML, CSS, and JS framework for developing responsive, mobile first projects on the web: Bootstrap. São Francisco, 2016. Disponível em: <http://getbootstrap.com/>. Acesso em: 13 fev. 2016.

GONZALEZ, M.; LIMA, V. L. S. Recuperação de informação e processamento da linguagem natural. Porto Alegre: Pontifícia Universidade Católica do Rio Grande do Sul, 2003. Disponível em: <http://www.inf.pucrs. br/ - gonzalez/docs/minicurso-jaia2003.pdf>. Acesso em: 23abr.2014.

GRACIANO, M. I. G. et al. Aspectos sociofamiliares constitutivos do estudo social de adolescentes com fissura labiopalatina. Arquivos de Ciências da Saúde, São José do Rio Preto, v. 22, n. 1, p. 79-84, 2015.

LEVINE, R. I.; DRANG, D. E.; EDELSON, B. Inteligência Artificial e Sistemas Especialistas: aplicaçóes e exemplos práticos. São Paulo: McGraw-Hill, 1988.

LIDDLE, T. L.; YORKE, L. Coordenação motora. São Paulo: Makron Books, 2006.

MACEDO, R. L. Interpretador AIML alimentado com tags HTML5. In: CONGRESSO DE PESQUISA CIENTÍFICA: INOVAÇÃO, ÉTICA E SUSTENTABILIDADE, 2., 2012, Marília. Anais... Marília: UNIVEM, 2012. p. 48-55.

MELO, T. M. et al. Capacitação de agentes comunitários de saúde em saúde auditiva: efetividade da videoconferência. Pró-Fono Revista de Atualização Científica, Barueri, v. 22, n. 2, p. 139-144, 2010.

NUNES, J. A.; CUNHA, M. C. Relaçôes entre diagnóstico do CID-10 e características do processo de hospitalização de recém-nascidos em unidade de terapia intensiva neonatal. Distúrbios da Comunicação, São Paulo, v. 26, n. 1, p. 70-76, 2014.

OLIVEIRA, H. T. A. Dr. Pierre: um chatterbot com intenção e personalidade baseado em ontologias para apoiar o ensino de psiquiatria. In: SIMPÓSIO BRASI- 
LEIRO DE INFORMÁTICA NA EDUCAÇÃO, 21., 2010, João Pessoa. Anais... João Pessoa, 2010. p. 1-10.

PARRA FILHO, D.; SANTOS, J. A. Metodologia cientifica. São Paulo: Futura, 1998.

PHP GROUP.PHP is a popular general-purpose scripting language that is especially suited to web development. Disponível em: <http://www.php.net>. Acesso em: 23 fev 2016.

PIAGET, J. A construção do real. Rio de Janeiro: Zahar, 1967.

PIAGET, J. A formação do símbolo na criança, imitação, jogo, sonho, imagem e representação de jogo. Sáo Paulo: Zahar, 1971.

PIAGET, J. O nascimento da inteligência na criança. Rio de Janeiro: Editora Guanabara, 1991.

PICOLINI, M. M. et al. A Elaboração de um ambiente virtual de aprendizagem em síndromes genéticas. Revista CEFAC, São Paulo, v. 15, n. 2, p. 382-390, 2013.

PINTO, E. B.; VILANOVA, L. C. P.; VIEIRA, R. M. $O$ desenvolvimento do comportamento da criança no primeiro ano de vida: padronização de uma escala para avaliaçáo e acompanhamento. São Paulo: Casa do Psicólogo, FAPESP, 1997.

PRIDHAM, K. A.et al. Guiding mothers' management of health problems of very low birth-weight infants. Public Health Nursing, Boston, v. 23, n. 3, p. 205-215, 2006.

SILVA FILHO, O. G.; FREITAS, J. A. S. Caracterização morfológica e origem embrionária. In: TRINDADE, I. E. K.; SILVA FILHO, O. G. Fissuras labiopalatinas: uma abordagem interdisciplinar. São Paulo: Santos, 2007. p. 17-49.

SIQUEIRA, A. A. Processamento de Linguagem Natural na recuperação de informaçóes numéricas em textos não es- truturados. 2011. 115 f. Trabalho de Conclusão de Curso (Graduação em Engenharia da Computação) - Universidade Federal do Vale do São Francisco, Juazeiro, 2011.

TRINDADE, I. E. K.; SILVA FILHO, O. G. Fissuras labiopalatinas: uma abordagem interdisciplinar. São Paulo: Santos, 2007.

UNIVERSITY ROLLINS SCHOLL OF PUBLIC HEALTH. Health-related web site evoluation. Atlanta, 1998. Disponível em: <http://www.sph.emory.edu/WELLNESS/instrument.html>. Acesso em: $10 \mathrm{dez} .2013$.

VIEIRA, P. B.; DANIELSKI, K. O compartilhamento do cuidado entre a equipe de enfermagem e os pais de crianças hospitalizadas. Revista Cientifica CENSUPE, Joinville, n. 2, p. 109-119, 2014.

WAKEFORD, L. et al. Telerehabilitation position paper. American Journal of Occupational Therapy, Rockville, v. 58, n. 6, p. 656-660, 2005.

WERNER, D. Guia de deficiências e reabilitação simplificada: para crianças e jovens portadores de deficiência, famílias, comunidades, técnicos de reabilitação e agentes comunitários de saúde. Brasília: Coordenadoria Nacional para Integração da Pessoa Portadora de Deficiência - CORDE, 1994.

WILlIAMS, L. C. A.; AIELLO, A. L. R. O Inventário Portage operacionalizado: intervenção com famílias. São Paulo: Memnon, 2001.

WORLD HEALTH ORGANISATION - WHO. Telemedicine: opportunities and developments in member states. Geneva, 2010.

ZAMBONATO, T. C. F. Teleducação interativa: intercâmbio técnico-científico entre profissionais atuantes com fissura labiopalatina. 2012. $127 \mathrm{f}$. Tese (Doutorado em Fissuras Orofaciais) - Universidade de São Paulo, Bauru, 2012.

\section{Contribuição de Autores}

Lyana: Levantamento de dados e concepção do texto. Márcia Cristina, Élvio Gilberto, Luciana Paula: Orientação e correçóes do texto. Caroline e Patrick: Organização de fontes e revisão do texto. Hélcio e Leonardo: Levantamento de dados e revisão do texto. Todos os autores aprovaram a versão final do texto.

\section{Notas}

${ }^{1}$ Este artigo é resultado da pesquisa realizada como Tese de Doutorado em Ciências da Reabilitação em andamento. O projeto foi submetido e aprovado pelo Comitê de Ética em Pesquisa do HRAC/USP sob parecer de n 637.576 e CAEE 28274814.4.0000.5441. 